\title{
Propriedades de fluxo de produtos pulverulentos alimentícios
}

\author{
José P. Lopes Netoㅁ, Valneide R. da Silva² \& José W. B. do Nascimento²
}

\begin{abstract}
RESU MO
Visando fornecer maiores informações sobre o fluxo de produtos sólidos industriais, a presente pesquisa determinou as propriedades de fluxo de quatro produtos pulverulentos fabricados por indústrias de alimentos e analisou os seus níveis de escoabilidade, em função do tempo de consolidação. $\mathrm{N}$ a obtenção dos dados se utilizou 0 aparelho de cisalhamento direto de translação, com base na célula de cisalhamento de Jenike e bancada de consolidação. Para determinação do índice de fluxo (ffc) e, do diâmetro mínimo do orifício de descarga (D), adotou-se a metodologia de Jenike enquanto para o ângulo mínimo de inclinação da tremonha cônica lançou-se mão da metodologia de Enstad. Conclui-se que os tempos de consolidação estudados não afetaram as propriedades de fluxo dos produtos pulverulentos e que a inclinação mínima da tremonha para permitir o fluxo seja de $60^{\circ}$. Q uanto ao orifício de descarga, seu valor pôde ser determinado pela metodologia de Jenike apenas para a farinha de trigo com valor mínimo de $1,1 \mathrm{~m}$ para o período de $24 \mathrm{~h}$ de consolidação.
\end{abstract}

Palavras-chave: descarga, produtos industriais, tremonha cônica

\section{Flow properties of powdered food products}

\begin{abstract}
Trying to provide more information about the flow of industrial solid materials, this research determined the flow properties of four powdered products manufactured by food industries and examined their levels of flowability, depending on the time of consolidation. The tests were conducted in the Jenike shear cell machine and consolidation bench. For determination of the flow index (FFC) and minimum diameter of the discharge orifice (D) Jenike's methodology was used and for minimum angle of the hopper, the Enstad's method was adopted. It may be concluded that the consolidation time studied did not affect the flow properties of powdered materials and the minimum inclination of hopper angle was $60^{\circ}$. It was possible to determine the discharge orifice by Jenike's method only in case of wheat flour with a minimum value of $1.1 \mathrm{~m}$ for 24-hour period of consolidation.
\end{abstract}

Key words: discharge, industrial powder, conical hopper

1 UATA/UFCG, Rua Coronel João Leite 815, Centro, CEP 58840-000, Pombal, PB. Fone: (83) 3431-2376. E-mail: lopesneto@gmail.com

2 UAEA/UFCG, Rua Aprígio Veloso 882, Centro, CEP 58109-900, Campina Grande, PB. Fone: (83) 3310-1482. E-mail: rval707@yahoo.com.br; wallace@deag.ufcg.edu.br 


\section{INTRODUÇÃO}

Obteve-se, nas últimas décadas, um grande avanço científico sobre o fluxo de produtos sólidos em silos, sobretudo quanto ao conhecimento de problemas relacionados ao seu manuseio e armazenagem em escala industrial, o qual foi agravado pelo surgimento, nos últimos anos, em quantidade e variedade, de uma gama de novos produtos sólidos. Com isto, as indústrias foram obrigadas a desenvolver novos sistemas de armazenagem, manuseio e transporte cada vez mais eficientes a fim de que as etapas de produção industrial fossem realizadas de forma satisfatória.

Em geral, as indústrias têm problemas com seus produtos, sejam eles na forma granular ou pulverulenta, uma vez que os sólidos, ao contrário dos líquidos, transmitem tensões de cisalhamento em condições estáticas e, quando comprimidos, aumentam sua coesão, proporcionando interferências na descarga e, em conseqüência, paralisações parciais ou totais do processo industrial, o que pode acarretar sérios prejuízos econômicos.

Dentre os principais obstáculos enfrentados pelas indústrias que manuseiam produtos pulverulentos se destacam a formação de arcos coesivos capazes de restringir, parcial ou completamente, a descarga cuja ocorrência está intrinsecamente relacionada às geometrias dos silos e tremonhas, às propriedades físicas e de fluxo dos produtos sólidos e condições ambientais como pressão, temperatura e umidade.

Como prevenção a esses obstáculos, recomenda-se investigação ampla das propriedades de fluxo e físicas dos produtos que serão utilizados; somente desta forma será possível predizer tipo de fluxo mais adequado dos produtos armazenáveis em silos e evitar obstruções na descarga, maximizando operações de descargas, transilagem, dosagem e empacotamento (Juliano et al., 2006).

Jenike (1964) definiu dois tipos básicos de fluxo que, hoje, são adotados por todas as normas internacionais de fluxo e ações em silos. O fluxo de massa ocorre quando o produto entra substancialmente em movimento, em todas as partes do silo, imediatamente após a abertura do orifício de descarga (ocorre quando as paredes da tremonha são suficientemente inclinadas e lisas e não existem transições abruptas); já o fluxo de funil se dá quando apenas parte do produto entra em movimento através de um canal vertical formado no interior do silo; outro fator de influência considerável no tipo de fluxo dos produtos sólidos é o tempo efetivo de armazenagem. Quando o produto é submetido a um estado de tensão de compressão durante determinado tempo, pode adquirir resistência e formar arcos coesivos. Porém, quando o orifício de descarga não é adequadamente projetado e o produto é submetido a longo tempo de armazenamento, esses arcos coesivos podem ocasionar a parada do escoamento do produto acarretando problemas estruturais, como deformações e flambagens locais nas paredes dos silos.

Para estimar a possibilidade dos sólidos fluir por gravidade, é necessário determinar a função fluxo (FF), que é uma reta gerada no gráfico com coordenadas de tensões principais e tensões de não confinamento em que a inclinação define o grau de escoabilidade do sólido. Esta inclinação é bastante influenciada pelo tempo de armazenagem (Nascimento, 1996). Uma forma de se considerar os efeitos das propriedades físicas e condições externas nas propriedades de fluxos como função do tempo de armazenagem, seria a medição da Função Fluxo (FF) dos sólidos após determinado tempo de armazenagem; a esta função se atribui o nome de Função Fluxo Temporal (FFt).

Em relação a este contexto se objetiva, com este trabalho, determinar as propriedades de fluxo de quatro produtos pulverulentos fabricados por indústrias de alimentos e analisar os seus níveis de escoabilidade, em função do tempo de consolidação.

\section{MATERIAL E MÉTODOS}

Foram escolhidos e testados quatro produtos alimentícios industriais obtidos no comércio local de Campina Grande, PB; são eles: farinha de trigo, amido de milho, fécula de mandioca e farinha de milho.

A determinação dos seus teores de umidade foi realizada pelo Método da estufa na qual se colocou uma amostra previamente pesada de cada produto, a temperatura de $105^{\circ} \mathrm{C}$ e, após por $24 \mathrm{~h}$, a amostra foi retirada e novamente pesada. Determinou-se através da diferença de massa, o teor de água perdido em base úmida; a granulometria foi definida por peneiramento, colocando-se $500 \mathrm{~g}$ de cada produto em jogo de peneiras e agitador elétrico, durante 15 min.

A metodologia adotada para a determinação das propriedades de fluxo dos produtos foi a recomendada pela BMHB (1985) com o uso do aparelho de cisalhamento direto translacional (Jenike Shear Cell) (Figura 1). Para a determinação das propriedades de fluxo em função do tempo de armazenagem (temporal), após a fase de pré-cisalhamento, cada amostra foi transferida para a bancada de consolidação (Figura 2) onde permaneceram durante 24 e 48 h sob a ação de cargas normais predefinidas (Tabela 1); decorrido este período, as células foram transferidas para o aparelho de cisalhamento direto e determinada a tensão de

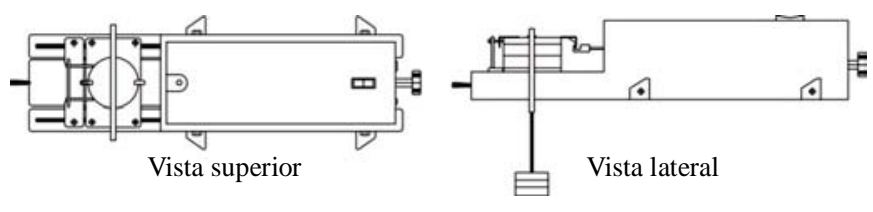

Figura 1. A parelho de cisal hamento direto

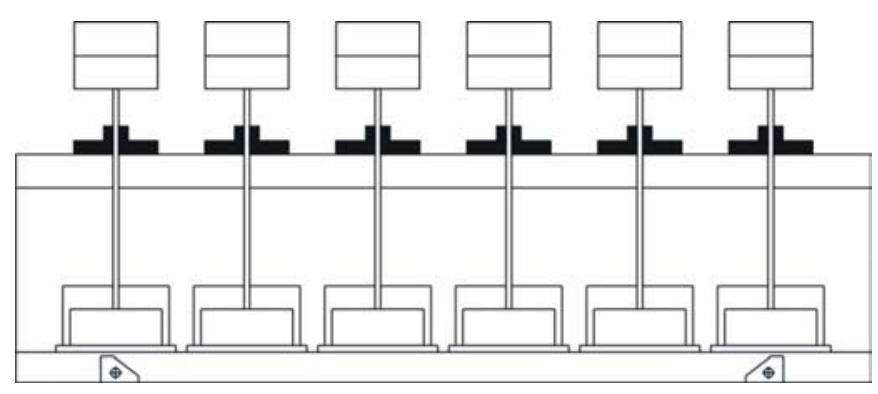

Figura 2. Bancada de consolidação 
cisalhamento, em função do tempo. A bancada de consolidação tem capacidade para seis amostras inseridas em uma cápsula de acrílico para evitar que a umidade do ar externo interfira nos testes.

Tabela 1. Níveis de carga normal utilizados nos ensaios

\begin{tabular}{cccc}
\hline Pré-cisalhamento (N) & \multicolumn{3}{c}{ Cisalhamento (N) } \\
100 & 70 & 50 & 35 \\
70 & 50 & 35 & 20 \\
50 & 35 & 20 & 10 \\
\hline
\end{tabular}

Para a determinação do ângulo de atrito com a parede $\left(\varphi_{\mathrm{w}}\right)$, utilizou-se o mesmo equipamento e a mesma célula de cisalhamento, substituindo-se apenas o anel inferior pela amostra do material da parede, enquanto os níveis de carga normais foram: $50,40,30,20,10$ e 4,4 N. A superfície utilizada nos ensaios foi aço inoxidável por se tratar de material recomendado na construção de silos destinados à armazenagem de produtos alimentícios industrializados.

Para a obtenção do índice de fluxo (ffc), utilizou-se o valor médio das razões entre a tensão principal de consolidação $\left(\sigma_{\mathrm{M}}\right)$ e a tensão não confinada de deslizamento $\left(\mathrm{f}_{\mathrm{C}}\right)$ e se adotaram, para a classificação dos produtos, os índices propostos por Jenike (1964) constantes na Tabela 2, enquanto o orifício mínimo de descarga (D) foi calculado conforme método de Jenike (1964) através da Eq. 1 dada por:

$$
\mathrm{D}=\frac{\mathrm{H}(\theta) \sigma_{\mathrm{cr}}}{\gamma}
$$

donde:

$$
\begin{aligned}
& H(\theta) \text { - valor em uma função do ângulo de inclinação } \\
& \text { da tremonha } \\
& \sigma_{c r} \text { - tensão crítica não confinada } \\
& \gamma \text { - peso específico consolidado }
\end{aligned}
$$

Tabela 2. Índice de escoabilidade ou índice de fluxo proposto por (Jenike, 1964)

\begin{tabular}{cc}
\hline Tipos de fluxo & Índice de fluxo $\left(\mathrm{ff}_{\mathrm{c}}\right.$ ) \\
Sem fluxo & $\mathrm{ff}_{\mathrm{c}}<1$ \\
Muito coesivo & $1<\mathrm{ff}_{\mathrm{c}}<2$ \\
Coesivo & $2<\mathrm{ff}_{\mathrm{c}}<4$ \\
Fácil & $4<\mathrm{ff}_{\mathrm{c}}<10$ \\
Livre & $\mathrm{ff}_{\mathrm{c}}>10$ \\
\hline
\end{tabular}

Adotou-se, para a determinação do ângulo de inclinação mínimo da tremonha cônica com a horizontal $(\theta)$, a teoria de Enstad (1981). Todos os ensaios foram realizados em laboratório com temperatura ambiente e umidade relativa do ar constantes, a $24{ }^{\circ} \mathrm{C}$ e $65 \%$, respectivamente.

\section{RESULTADOS E DISCUSSÃO}

Determinaram-se, através dos ensaios granulométricos, os maiores percentuais retidos dos pós alimentícios nas penei- ras de abertura $0,075 \mathrm{~mm}(74,7 \%)$ para a farinha de trigo, abertura $<53 \mu \mathrm{m}(58,8$ e $51,4 \%)$ para amido de milho e fécula de mandioca, respectivamente, e peneira de abertura $0,149 \mathrm{~mm}(70,2 \%)$ para farinha de milho. Durante os ensaios, o teor de umidade médio dos produtos foi de 13,5, 12,2, 12,6 e $13,1 \%$ para a farinha de trigo, amido de milho, fécula de mandioca e farinha de milho, respectivamente.

$\mathrm{Na}$ Tabela 3 se encontram os resultados das propriedades de fluxo dos produtos nas condições instantânea e temporal. As propriedades peso específico consolidado $(\gamma)$, ângulo de atrito interno $(\varphi)$ e ângulo efetivo de atrito interno $(\delta)$ são apresentados em seus valores máximos e mínimos possibilitando, assim, o projeto de silos através do método dos estados limites. Como o Brasil ainda não tem uma norma específica de dimensionamento de silos, aconselha-se utilizar

\begin{tabular}{|c|c|c|c|c|c|c|c|}
\hline \multirow{2}{*}{ Produto } & \multicolumn{2}{|c|}{$\gamma\left(\mathrm{kN} \mathrm{m}^{-3}\right)$} & \multirow{2}{*}{$\mathrm{ff}_{\mathrm{c}}$} & \multicolumn{2}{|c|}{$\varphi\left(^{\circ}\right)$} & \multicolumn{2}{|c|}{$\delta\left({ }^{\circ}\right)$} \\
\hline & $\gamma_{i}$ & $\gamma_{\mathrm{s}}$ & & $\varphi_{\mathrm{i}}$ & $\varphi_{\mathrm{s}}$ & $\delta_{i}$ & $\delta_{\mathrm{s}}$ \\
\hline \multicolumn{8}{|c|}{ Instantâneas $(\mathrm{t}=0)$} \\
\hline A & 7,5 & 7,9 & 10,4 & 37,6 & 38,3 & 39,8 & 42,3 \\
\hline B & 6,3 & 6,7 & 30,2 & 38,7 & 42,3 & 41,8 & 44,2 \\
\hline C & 6,8 & 7,1 & 31,1 & 32,4 & 35,5 & 34,9 & 38,1 \\
\hline D & 7,1 & 7,4 & 31,9 & 41,7 & 45,8 & 46,2 & 47,7 \\
\hline \multicolumn{8}{|c|}{ Temporal - consolidado $(\mathrm{t}=24 \mathrm{~h})$} \\
\hline A & 7,5 & 7,6 & 8,3 & 39,1 & 42,4 & 40,7 & 42,5 \\
\hline B & 7,3 & 7,4 & 16,0 & 37,6 & 40,4 & 38,8 & 41,8 \\
\hline C & 7,4 & 7,5 & 13,2 & 29,7 & 36,9 & 31,3 & 38,7 \\
\hline $\mathrm{D}$ & 7,4 & 7,5 & 15,6 & 42,8 & 47,2 & 45,6 & 48,0 \\
\hline \multicolumn{8}{|c|}{ Temporal - consolidado $(\mathrm{t}=48 \mathrm{~h}$ ) } \\
\hline A & 7,5 & 7,6 & 7,9 & 36,8 & 40,3 & 39,0 & 42,2 \\
\hline B & 7,3 & 7,4 & 8,7 & 34,0 & 37,8 & 34,8 & 38,9 \\
\hline C & 7,3 & 7,5 & 9,1 & 30,4 & 36,7 & 31,2 & 37,3 \\
\hline D & 7,5 & 7,6 & 14,5 & 44,5 & 48,4 & 45,4 & 48,7 \\
\hline
\end{tabular}
normas internacionais para o cálculo das pressões e, dentre as existentes, a AS 3774 (1996) recomenda a utilização dos estados limites em projetos de silos.

Tabela 3. Propriedades de fluxo dos produtos analisados*

Para o peso específico consolidado, que representa a razão entre a massa sob ação de cargas de consolidação e o volume ocupado pela amostra, não houve alteração significativa em seus valores quando comparados os resultados instantâneos aos obtidos nos ensaios de consolidação (temporal) sendo a maior diferença da ordem de aproximadamente $15 \%$, registrada para o amido de milho correspondente ao período de $48 \mathrm{~h}$ de consolidação; este incremento em sua propriedade ocorreu, provavelmente, em razão deste produto possuir glicose em sua constituição molecular e, quando submetido à ação de carga normal em função do tempo, deuse ligação das moléculas, tornando-o mais denso.

Apesar dos produtos analisados demonstrarem ser pouco sensíveis a alterações em seus resultados de peso específico nos tempos analisados, observou-se grande variação no índice de fluxo ( $\mathrm{ff}_{\mathrm{c}}$ ) (Figura 3) quando se compararam os resultados instantâneos aos consolidados, sobretudo para o amido de milho, fécula de mandioca e farinha de milho. 


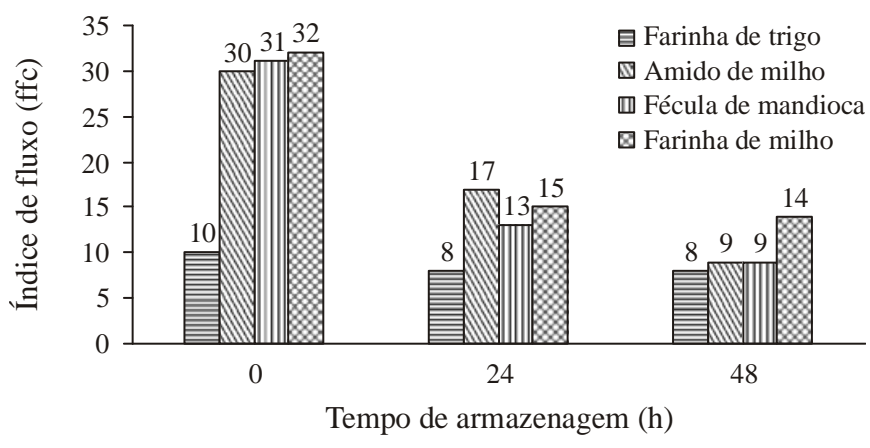

Figura 3. Índice de fluxo (ffc) dos alimentos

O índice de fluxo instantâneo (ffc) do amido de milho, fécula de mandioca e farinha de milho, atingiu valores de 30 , 31 e 32 , respectivamente, contrastando com o obtido para a farinha de trigo (10); entretanto, sob efeito das cargas de consolidação, tais valores sofreram uma redução de até três vezes e meia, atingindo valores de 9 para o amido de milho e fécula de mandioca e de 14 para a farinha de milho; já para a farinha de trigo, a redução foi mais sensível e seu valor reduzido em $20 \%$. Pode-se observar, pelo comportamento do índice de fluxo ao longo do tempo, tendência de aumento da resistência ao escoamento dos produtos e, se o teor de umidade fosse alterado, certamente alteraria sua classificação, haja vista que os produtos são pulverulentos e higroscópicos.

Uma explicação para o efeito ocorrido com o amido de milho, fécula de mandioca e farinha de milho, é a capacidade de um produto se tornar gradualmente mais compacto sob ação de consolidação devido à existência de maior número de regiões de contato, oriundas do rearranjo de partículas e de deformações plásticas sofridas; desta forma, esses efeitos podem ter ocorrido, uma vez que suas dimensões de partículas são bastante reduzidas.

O mesmo fato foi observado por Malby et al. (1993) quando afirmaram que as maiores interações entre as forças envolvidas no sistema conduzem a maiores valores de coesão com o decorrer do tempo. Teunou \& Fitzpatrick (2000) ainda complementam que as interações entre forças envolvidas na coesão do produto podem requerer determinado tempo para se desenvolverem e, desta forma, a coesão sobre a ação do tempo pode tornar-se gradualmente maior, porém o reduzido valor inicial de ffc para a farinha de trigo se deve ao fato deste produto ser mais sensível à compressão, em função de características inerentes à sua constituição física, como tamanho de partículas e teor de umidade e que apenas as cargas aplicadas na etapa de pré-cisalhamento da amostra na fase instantânea já tenham sido suficientes para que o produto desenvolvesse o valor de coesão de 780 Pa quando comparado com os outros alimentos analisados (amido de milho $=590 \mathrm{~Pa}$, fécula de mandioca $=294 \mathrm{~Pa}$ e farinha de milho = $763 \mathrm{~Pa}$ ) refletindo, assim, em um índice de fluxo inicial reduzido quando comparado com os demais produtos; tal hipótese pode ser reforçada pelo fato do valor de densidade consolidada ser ligeiramente maior que dos demais produtos alimentícios.

Lopes Neto et al. (2007) ao analisarem a escoabilidade de rações avícolas para diferentes fases de criação, obtive- ram valores de $\mathrm{ff}_{\mathrm{c}}$ iguais a 4 para as rações iniciais e engorda e 8,7 para a ração de terminação, enquanto Fitzpatrick et al. (2003) obtiveram valores de índice de fluxo de 6 e de aproximadamente 2 para amostras de leite com 0,9 e $73 \%$ de teor de gordura, respectivamente. Tanto os estudos de Lopes Neto et al. (2007) quanto os de Fitzpatrick et al. (2003) demonstraram a influência de componentes como gorduras e óleos, ácidos e as dimensão de partículas na variação do índice de fluxo de cada produto.

Lopes Neto et al. (2007) afirmam que uma compreensão completa deste comportamento é uma tarefa difícil pelo fato de existirem elementos não considerados como conservantes, sais, ácidos, óleos e gorduras, que podem influenciar nas propriedades físicas e de fluxo de produtos alimentícios. Sabe-se que pós alimentícios são complexos e de difícil caracterização em virtude de sua composição variada, da distribuição de partículas e da presença de elementos nas fases sólida, líquida e gasosa.

Nascimento (1996) cita que alguns dos principais fatores responsáveis por afetar a escoabilidade de sólidos em silos e tremonhas, são: teor de umidade, umidade relativa, temperatura, pressão, teor de gordura, dimensões de partículas e adições de agentes de fluxo.

Quanto à classificação de sua escoabilidade em função dos valores atribuídos ao $\mathrm{ff}_{\mathrm{c}}$ por Jenike (1964) (Tabela 2), diz-se que os quatro alimentos são classificados como de fluxo livre na fase instantânea; na fase de consolidação de 24 h, apenas a farinha de trigo tem sua classificação alterada para fluxo do tipo fácil, enquanto em $48 \mathrm{~h}$ de consolidação somente a farinha de milho permanece com classificação de fluxo livre sendo os demais classificados como de fácil escoabilidade.

Em relação aos ângulos de atrito interno $(\varphi)$ e ângulos efetivos de atrito interno $(\delta)$, ainda na Tabela 3 , não foi identificada variação significativa entre os períodos de consolidação estudados nem entre os produtos escolhidos, valendo destacar apenas que os valores ligeiramente maiores foram registrados para a farinha de milho, nos três tempos de consolidação.

$\mathrm{Na}$ Tabela 4 se encontram os ângulos de atrito com a parede de aço liso sendo os menores valores registrados para a farinha de milho enquanto os maiores foram obtidos para o amido de milho.

Tabela 4. Ângulo de atrito dos produtos com a parede

\begin{tabular}{lcc}
\hline \multirow{2}{*}{ Produto } & \multicolumn{2}{c}{ Aço liso } \\
\cline { 2 - 3 } Farinha de trigo & $\varphi_{\text {wi }}$ & $\varphi_{\text {ws }}$ \\
Amido de milho & 10,4 & 13,2 \\
Fécula de mandioca & 13,2 & 17,7 \\
Farinha de milho & 11,7 & 13,4 \\
\hline
\end{tabular}

Os índices "i" e "s" representam os valores inferior e superior das propriedades

Na Figura 4 estão dispostas as Funções fluxo instantânea $(0 \mathrm{~h})$ e temporal (FFt) dos produtos, nas condições de armazenagem 24 e 48 h. Observa-se que as curvas de Função fluxo instantânea (Figura 4A) para os quatro alimentos se encontram mais próximas ao eixo horizontal e, a medida em que 
o tempo de consolidação aumenta, suas inclinações passam a aumentar assumindo uma condição com tendência à verticalização. Tal efeito corrobora com o ocorrido com o índice de fluxo uma vez que uma curva mais próxima ao eixo horizontal representa um produto de fluxo fácil enquanto, seguindo uma direção anti-horária, este produto tende a apresentar maior resistência ao escoamento.

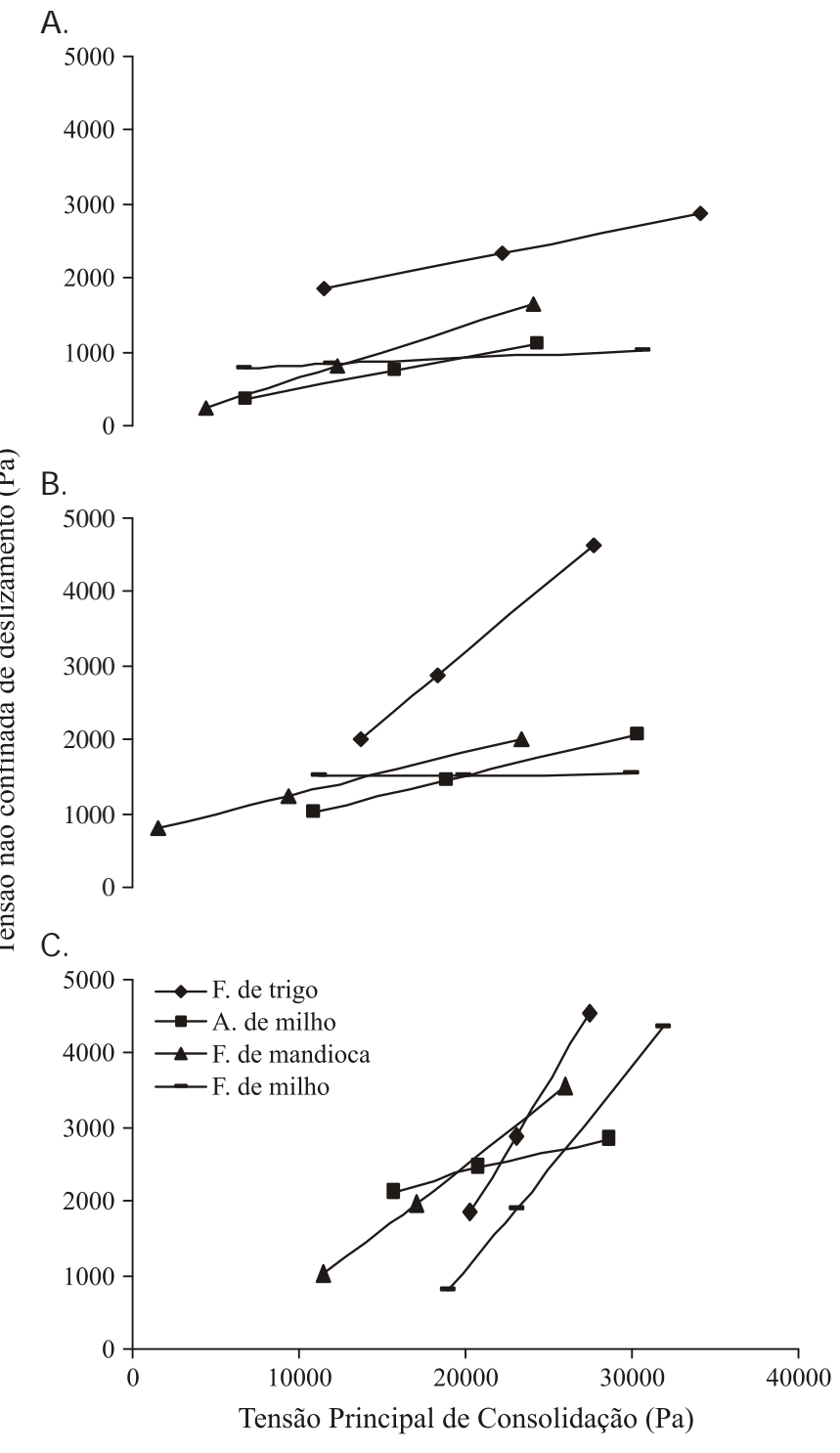

Figura 4. Função fluxo dos produtos. (A) Instantânea, (B) Consolidada 24 h, (C) Consolidada $48 \mathrm{~h}$

A Função fluxo de um produto (FF) é obtida através da construção de gráfico no qual é plotada a tensão não confinada de deslizamento $\left(f_{C}\right)$ versus tensão principal de consolidação $\left(\sigma_{\mathrm{M}}\right)$ que representa o esforço atuante no produto quando em situação de consolidação (Fitzpatrick et al., 2004). Observa-se, com o decorrer do período de armazenagem, que os valores de tensão de consolidação dos alimentos permaneceram praticamente inalterados, enquanto os valores de tensão não confinada $\left(\mathrm{f}_{\mathrm{C}}\right)$ foram gradativamente elevados.

$\mathrm{Na}$ Tabela 5 se encontram os valores de fator fluxo da tremonha (ff), inclinação de tremonha $\left(\theta_{\mathrm{m}}\right)$ tensão crítica $\left(\sigma_{\mathrm{cr}}\right)$ e dimensão do orifício de descarga $\left(\mathrm{D}_{\mathrm{m}}\right)$. O fator fluxo da tremonha indica a escoabilidade do produto proporcionada pela tremonha, ou seja, quanto menor seu valor, melhor será a tremonha. A tensão crítica ocorre no ponto resultante da intersecção de ff com FF e representa a tensão mínima que deve ocorrer no orifício de descarga de forma a impedir a formação de arcos coesivos ou abóbadas.

Tabela 5. Características geométricas da tremonha cônica*

\begin{tabular}{|c|c|c|c|c|}
\hline \multirow{2}{*}{ Produtos } & \multicolumn{4}{|c|}{ Aço inoxidável } \\
\hline & ff & $\theta \mathrm{m}\left({ }^{\circ}\right)$ & $\sigma_{\mathrm{cr}}(\mathrm{Pa})$ & $\mathrm{Dm}(\mathrm{m})$ \\
\hline \multicolumn{5}{|c|}{ Instantânea $(t=0)$} \\
\hline A & 1,5 & 54,5 & 709,9 & 0,21 \\
\hline B & 1,4 & 60,5 & 565,9 & $\#$ \\
\hline C & 1,6 & 53,7 & 1027,1 & $\#$ \\
\hline D & 1,4 & 53,5 & \# & $\#$ \\
\hline \multicolumn{5}{|c|}{ Temporal - consolidação (t = 24 h) } \\
\hline A & 1,5 & 54,5 & 2345,3 & 0,71 \\
\hline B & 1,4 & 60,18 & 335,3 & $\#$ \\
\hline C & 1,6 & 53,8 & 75,7 & \# \\
\hline D & 1,3 & 53,56 & $\#$ & $\#$ \\
\hline \multicolumn{5}{|c|}{ Temporal - consolidação $(t=48$ h) } \\
\hline A & 1,5 & 54,5 & 3683,8 & 1,1 \\
\hline B & 1,5 & 59,7 & 1428,0 & $\#$ \\
\hline C & 1,6 & 53,4 & 799,7 & \# \\
\hline D & 1,3 & 53,7 & $\#$ & $\#$ \\
\hline
\end{tabular}

\# Valores não encontrados

* A (Farinha de trigo); B (Amido de milho); C (Fécula de mandioca); D (Farinha de milho)

Não se notou alteração significativa na inclinação da tremonha para os tempos de consolidação estudados, refletindo que o tempo máximo usado na pesquisa foi insuficiente para causar a exigência de tremonhas mais inclinadas quando comparados com os valores instantâneos, uma vez que se espera que produtos com maiores dificuldades de fluxo passem a necessitar de tremonhas com maiores ângulos de inclinação; entretanto, entre os produtos estudados os maiores valores foram registrados para o amido de milho e os menores foram obtidos para a fécula de mandioca e farinha de milho.

Em relação ao orifício de descarga, apenas para a farinha de trigo foi possível sua determinação, uma vez que não se obtiveram pontos de intersecção entre as curvas de ff e FF nos tempos instantâneo, 24 e 48 h, para os demais produtos. Fitzpatrick et al. (2004) afirmam que a metodologia de Jenike para a determinação do orifício de descarga pode, em alguns casos, calcular valores inesperados para o orifício de descarga como, por exemplo, pequenas dimensões de orifícios para produtos de elevada coesão; os autores afirmam, ainda, que esta discordância se deve ao fato da metodologia de Jenike ser extremamente sensível à variação dos valores das propriedades de fluxo sendo agravada pela dificuldade de se obter medições seguras das suas propriedades, com alta reprodutibilidade.

Este mesmo fenômeno de não cruzamento de ff com FF foi observado por Nóbrega \& Nascimento (2005) ao analisarem o fluxo de ração para aves com teor de gordura de $7,2 \%$ em silos com descarga excêntrica. De acordo com a 
BMHB (1985), quando a função fluxo de um produto não intercepta o fator fluxo da tremonha, o dimensionamento do orifício de descarga para produtos de fluxo livre deve ser efetuado em razão da vazão necessária para o silo com valor mínimo de 10 vezes o diâmetro médio das partículas.

\section{CONCLUSÕES}

1. Os tempos de consolidação estudados pouco alteraram as propriedades de fluxo dos quatro produtos testados, podendo classificá-los como de fluxo livre para a condição instantânea e de fluxo fácil para as condições de 24 e 48 h.

2 . As tremonhas de aço inox para os produtos alimentícios pulverulentos estudados devem ter inclinação mínima das paredes de $60^{\circ}$ de forma a permitir fluxo e não haver segregação durante a descarga.

3. A dimensão do orifício de descarga aumentou com o incremento do tempo efetivo de consolidação em $20 \%$ para a farinha de trigo atingindo diâmetro mínimo de $1,1 \mathrm{~m}$ para a condição de $48 \mathrm{~h}$ de consolidação.

4. Para os demais produtos, a metodologia de Jenike não se mostrou adequada devendo suas dimensões de descarga ser adotadas em razão da vazão de descarga desejada e das dimensões de partículas dos produtos.

\section{LITERATURA CITADA}

AS 3774. Australian Standard. Loads on bulk containers. Sydney: Australian Standard , 1996. 62p.

BMHB - British Materials Handling Board. Draft code of practice for the design of silos, bins, bunkers and hoppers. Berkshire: BMHB, 1985. 143p.
Enstad, G. G. A novel theory on the arching and doming in mass flow hoppers. Bergen: The Michelsen Institute, 1981. 172p.

Fitzpatrick, J. J.; Barringer, S. A.; Iqbal, T. Flow property measurement of food powders and sensitivity of Jenike's hopper design methodology to the measured values. Journal of Food Engineering, v.61, p.399-405, 2004.

Fitzpatrick, J. J.; Iqbal, T.; Delany, C.; Twomey, T.; Keogh, M. K. Effect of powder properties and storage conditions on the flowability of milk powders with different fat contents. Journal of Food Engineering, v.64, p.435-444, 2003.

Jenike, A. W. Storage and flow of silos. Bulletin 123. Salt Lake City: University of Utah, 1964. 89p.

Juliano, P.; Muhunthan, B.; Cánovas, G. V. B. Flow and shear descriptors of preconsolidated food powders. Journal of Food Engineering, v.72, n.2, p.157-166, 2006.

Lopes Neto, J. P.; Nascimento, J. W. B. do; Silva, V. R.; Lopes, F. F. M. Propriedade de fluxo e característica de escoabilidade de rações avícolas para dimensionamento de silos. Revista Ciência e Agrotecnologia, v.31, n.3, p.851-859, 2007.

Malby, L. P.; Enstad, G. G.; Silva, S. R. Investigation of the behavior of powders under and after consolidation. In: Reliable Flow of Particulate Solids Symposium, 1993, Oslo. Anais... Oslo: EFCHE, 1993. 12p.

Nascimento, J. W. B. do. Estudos de silos metálicos prismáticos para fábricas de ração. São Carlos: USP, 1996. 222p. Tese Doutorado

Nóbrega, M. V.; Nascimento, J. W. B. do. Fluxo de ração avícola em silos prismáticos com tremonha excêntrica. Revista Brasileira de Engenharia Agrícola e Ambiental, v.9, n.3, p.413-419, 2005.

Teunou, E.; Fitzpatrick, J. J. Effect of time and consolidation on food powder flowability. Journal of Food Engineering, v.43, p. $97-101,2000$. 